\title{
Constructing Measures Of CS Effectiveness To Boost Subjective Quality At Manufacturers
}

\author{
Akinori Ishikawa, Aoyama Gakuin University, Japan \\ Yuki Morita, Aoyama Gakuin University, Japan \\ Kakuro Amasaka, Aoyama Gakuin University, Japan
}

\begin{abstract}
Subjective quality features, such as product feel and design, are becoming increasingly important to consumers. This paper focuses on the linkages connecting business processes in product planning and design departments and constructs Measures of CS Effectiveness to quantitatively assess efforts to improve subjective quality features at both departments. The results of implementing these measures are reported.
\end{abstract}

Keywords: Subjective Quality; Measures of CS Effectiveness; Manufactures

\section{INTRODUCTION}

$\mathrm{n}$ recent years, consumers have been placing more importance on subjective quality factors such as the feel or design of a product. This has made it more important for product planning and design departments, which form the core of product manufacturing at corporations, to work toward achieving subjective quality. This paper defines customer satisfaction effectiveness as the ability of manufacturers' product planning and design departments to utilize customer information and effectively communicate. The researchers developed Measures of CS Effectiveness to quantitatively evaluate the level of CS effectiveness in each department, enabling companies to immediately identify any gaps between their approaches to subjective quality. The researchers thus offer a way to quantitatively assess the planning and design departments' approaches to subjective quality and pinpoint problem areas at a corporate or departmental level.

\section{BACKGROUND}

Today, new product planning tends to be based on new product concept ideas and fails to take customer needs into account. According to interviews with members of the design department at a certain domestic automaker, the development of new designs continues to be based only on the designers' rules of thumb. The experiential rules of expert designers are an important factor in generating fresh, innovative ideas, but a design process based exclusively on this method poses high risks for companies in terms of cost and marketability.

Customers typically judge current products in terms of whether they are good or bad, but they rarely have a clear image of the kind of things they might want in the future. Offering the products customers want, even before they want them, will be particularly important in developing and manufacturing future products. In order to do this, it is essential that companies clearly grasp the vague, subjective notions of their customers.

Expressing the images formed through customers' words (implicit knowledge) as a shared language (linguistic knowledge) and appropriately translating (turning into explicit knowledge) technical words (e.g. design drawings) using a correlation technique - in other words, changing the subjective into the objective-will be an important part of future product development. At the same time, it is important to use a correlation technique to change the objective data back into subjective information in order to use the diagrammed data to create physical objects that customers want. 


\section{IDENTIFYING KEY FACTORS IN IMPROVING SUBJECTIVE QUALITY}

Product planning and design departments were surveyed in order to identify what components to evaluate in judging CS effectiveness. The survey consisted of a single free response question that asked participants what they thought were the key factors in boosting customer satisfaction. They were asked to give their answers from two perspectives: utilization of customer information and communication between product planning and design departments.

Interviews were conducted at six manufacturers. Three were given in person during company visits, and three were done via email. The collected data were organized, eliminating duplicate responses, and were used to construct an affinity diagram. This yielded eight groups of key factors that product planning and design department members felt were important in terms of utilizing customer information and communication - business process, information gathering, information analysis, reliability and trust, transmitting information, sharing/centralizing information, infrastructure, and collaborative tasks between departments. Twenty specific factors were then identified in the eight groups. A summary of these key components can be found in Figure 1.

\section{CORE COMPONENT OF SUBJECTIVE QUALITY IMPROVEMENT}

\section{Groups of Factors that Boost CS Effectiveness}

In order to determine which customer information utilization and communication factors product planning and design departments consider to be most important in boosting customer satisfaction, it is necessary to weight each of the items for each department. To do this, staff working in departments in charge of product planning and design at manufacturing companies were given a survey where they were asked to rate each factor on a seven-point scale in terms of importance. Specifically, they were asked how important each of 20 evaluation items were in response to the question, "Do you think that $\mathrm{X}$ is important in increasing subjective product quality?"

\begin{tabular}{|c|c|c|}
\hline Information gathering & Transmitting information & Infrastructure \\
\hline Information item & Transmitted information & Information system \\
\hline Information volume & Received information & \multirow[t]{3}{*}{ Network infrastructure } \\
\hline Information accuracy & Product concepts & \\
\hline Up-to-date information & Design proposals & \\
\hline Information analysis & Business process & \multirow{3}{*}{$\begin{array}{c}\text { Collaborative tasks } \\
\text { between departments }\end{array}$} \\
\hline Analysis expertise & Improving $3 \mathrm{M}$ & \\
\hline Separation by segment & Work procedure & \\
\hline \multirow{2}{*}{$\begin{array}{c}\text { Sharing/centralizing } \\
\text { information } \\
\end{array}$} & Reliability and trust & \multirow[t]{4}{*}{ Information analysis } \\
\hline & Shared goal awareness & \\
\hline $\begin{array}{l}\text { Information } \\
\text { sharing/centralization }\end{array}$ & Standardization of & \\
\hline $\begin{array}{l}\text { Establishment of a } \\
\text { shared language }\end{array}$ & & \\
\hline
\end{tabular}

Figure 1: Extraction of Important Factor 


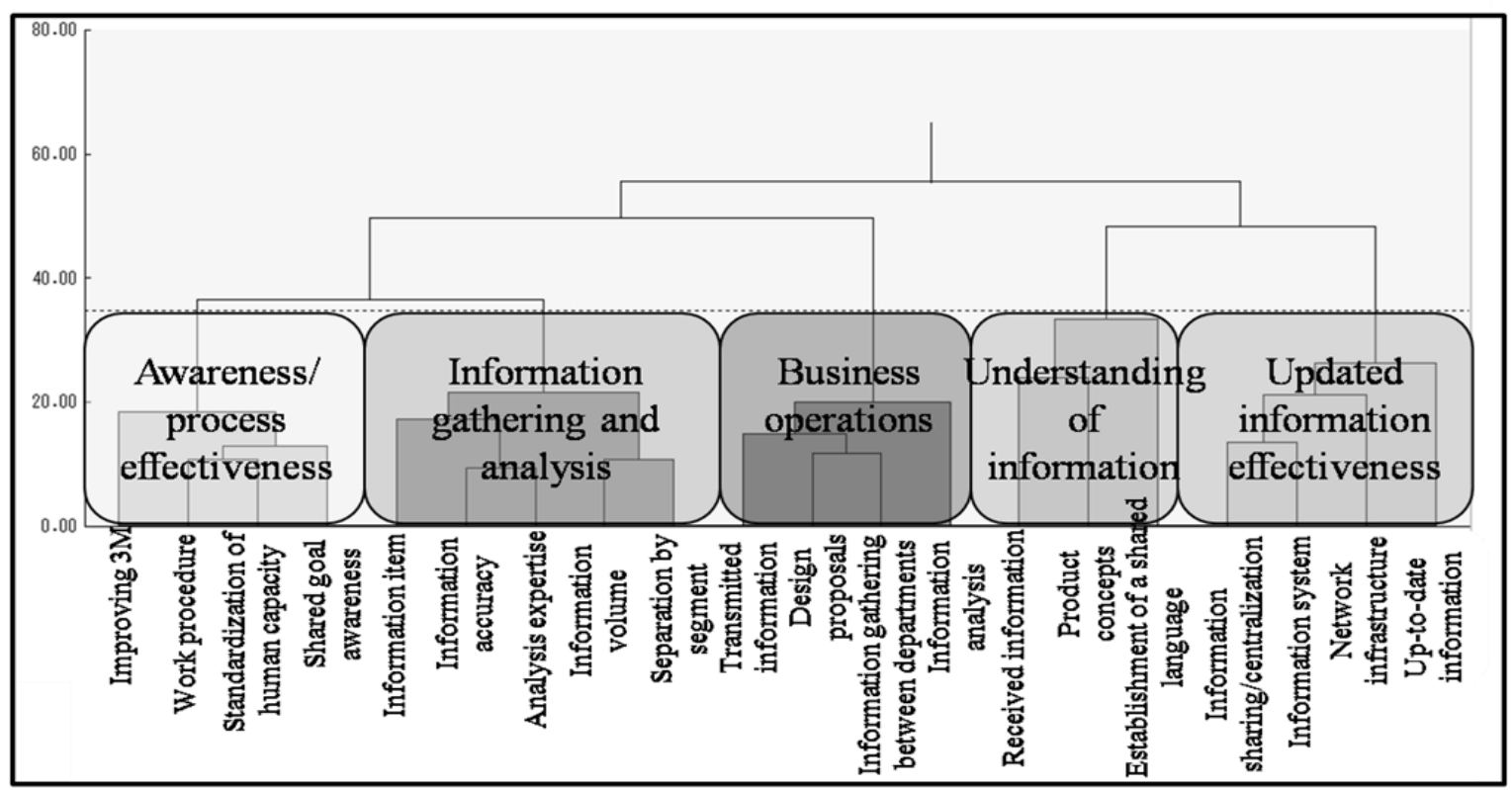

Figure 2: The Cluster Analysis Result of Design Departments

The resulting data were then separated into two categories, depending on which department it was collected from (product planning or design). This was done in order to find out which factors were considered important in terms of improving subjective product quality in each department - in other words, to identify the keys to boosting customer satisfaction effectiveness in both divisions. Here, we'll look for the factors that design departments considered important in improving subjective quality.

A cluster analysis was conducted on the 23 responses obtained from design department personnel. The purpose of the analysis was to categorize the 20 factors by looking at correlations in their level of importance. The results of this analysis are shown in Figure 2.

The cluster analysis revealed that the 20 factors that design departments considered to be important in boosting customer satisfaction could be grouped into five categories - awareness/process, information gathering/analysis, business operations, understanding of information, and updated information.

\section{Covariance Structure Analysis}

Next, a covariance structure analysis was conducted to ascertain which factors or groups both departments think contribute most to boosting CS effectiveness. Figure 3 shows a model of the covariance structure analysis and extracted results for design departments. This diagram shows the 20 factors (observed variables), five groups (latent variables), and CS effectiveness (latent variable). The 20 variables are considered a subordinate concept, the five groups an intermediate concept, and CS effectiveness a superordinate concept. This model is structured around the latent variables G1 through G5. Because each of the factors shows multicollinearity, Measures of CS Effectiveness that allow accurate scoring could not be generated.

Adding latent factors G1 through G5 to eliminate multicollinearity in the subordinate concept made it possible to extract the separate influence of the intermediate concept. 


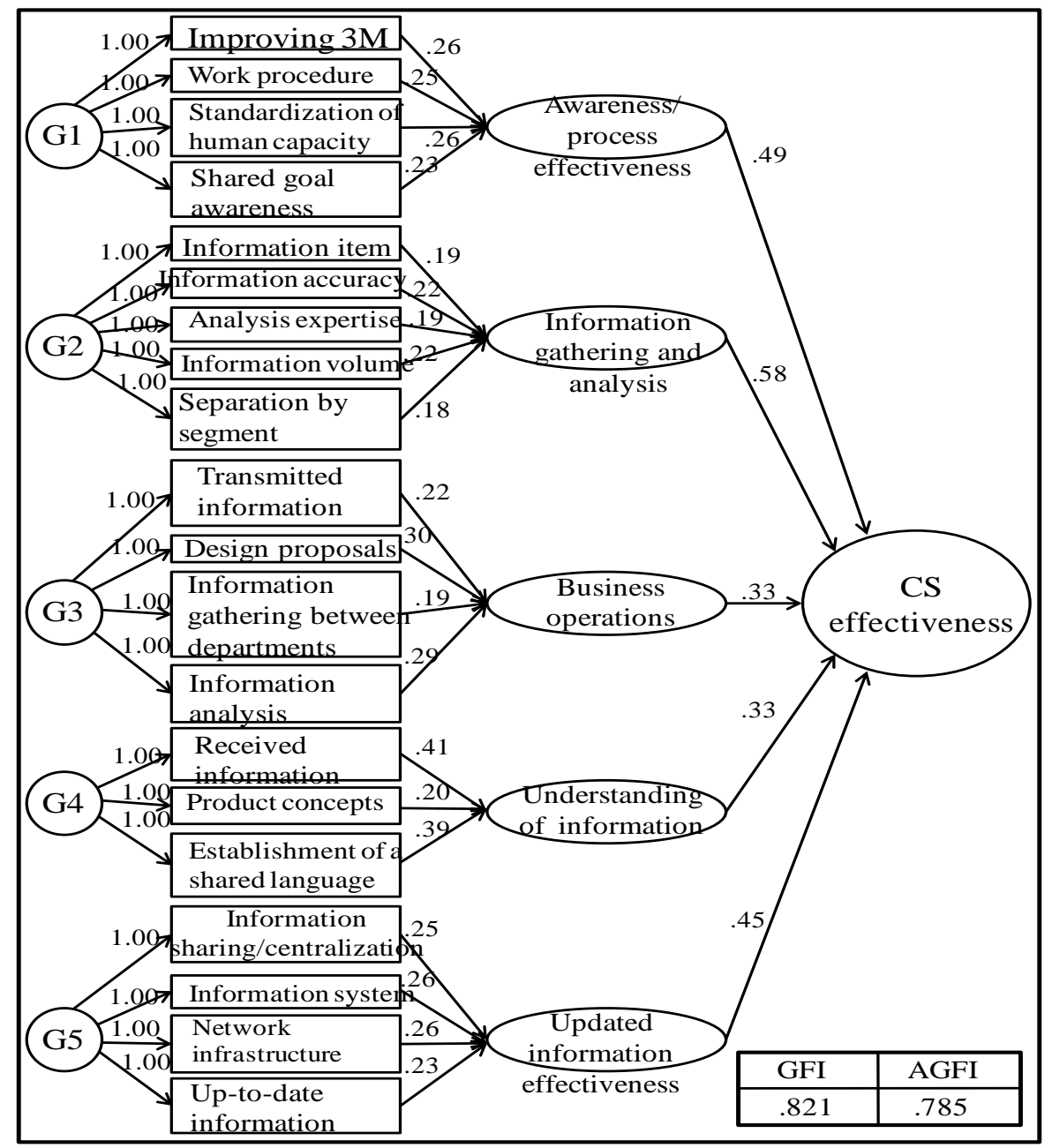

Figure 3: The Co-variance Structure Analysis Model

The goodness of fit index (GFI) for the covariate structure analysis model was 0.821 and the adjusted goodness of fit index (AGFI - an index that adjusts for instability in the model) was 0.785 . Here, the GFI is greater than or equal to the AGFI, and though this does not present a problem in this case because the difference is not great, a model where the AGFI is significantly lower than the GFI cannot be considered a good model. First, the influence of the 20 factors that make up the subordinate concept on the five groups that make up the intermediate concept will be examined using the example of the awareness/process effectiveness group. This group is made up of four factors and each has a coefficient of around 0.25 , indicating a balanced influence. Higher coefficients indicate stronger influence. The influence of the subordinate concept on the intermediate concept was identified by calculating the coefficients for the other four groups (information gathering and analysis, business operations, understanding of information, and updated information effectiveness).

Next, the influence of the intermediate concept (the five groups) on the superordinate concept (CS effectiveness) was identified. The information gathering and analysis group had a coefficient of 0.58 , making it the most descriptive of any of the five groups.

Using this method, the influence of the 20 factors on the five groups, and then the influence of the five groups on CS effectiveness in terms of what design departments felt improved subjective quality, were quantitatively identified. In order to identify the keys to evaluating CS effectiveness at product planning departments, a cluster analysis and principle component analysis were conducted in the same way to categorize the 
factors into groups, which were then weighted using covariance structure analysis according to their degree of influence on CS effectiveness.

\section{CREATING MEASURES OF CS EFFECTIVENESS TO BOOST SUBJECTIVE QUALITY}

Measures of CS Effectiveness were created by combining the evaluation coefficients obtained in the previous chapter with their current level of applicability.

First, Measures of CS Effectiveness (shown in Figure 4) were created for design departments. In order to express CS effectiveness using a 100-point scale, each of the five group coefficients were adjusted by multiplying them all by 6.553 .

Then, Measures of CS Effectiveness (shown in Figure 5) were created for product planning departments. In order to express CS effectiveness using a 100-point scale, each of the five group coefficients were adjusted by multiplying them all by 6.583 .

In this way, the researchers were able to arrive at a method of evaluating CS effectiveness based on the opinions of product planning and design departments.

\begin{tabular}{|c|}
\hline 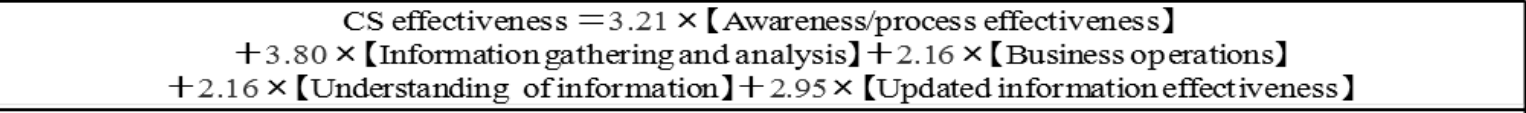 \\
\hline $\begin{aligned} \text { 【 Awareness/process effectiveness } \backslash & =0.26 \times(\text { Improving } 3 \mathrm{M})+0.25 \times(\text { Work procedure }) \\
& +0.26 \times(\text { Standardization of human capacity })+0.23 \times(\text { Shared goal awareness })\end{aligned}$ \\
\hline $\begin{array}{l}\text { 【 Information gathering and analysis } 】=0.20 \times(\text { Information item })+0.22 \times(\text { Information accuracy }) \\
+0.22 \times(\text { Information volume })+0.20 \times(\text { Analysis expertise })+0.18 \times(\text { Separation by segment })\end{array}$ \\
\hline $\begin{aligned} \text { 【 Business operations } 】 & =0.22 \times(\text { Transmitted information })+0.30 \times(\text { Design proposal }) \\
& +0.19 \times(\text { Information gathering between departments })+0.29 \times(\text { Information analysis })\end{aligned}$ \\
\hline $\begin{array}{c}\text { 【 Understanding of information 】 }=0.41 \times(\text { Received information })+0.29 \times(\text { Product concept }) \\
+0.39 \times(\text { Established of a shared language })\end{array}$ \\
\hline $\begin{array}{l}\text { 【 Updated information effectiveness 】 }=0.22 \times(\text { Information sharing/centralization }) \\
\quad+0.30 \times(\text { Network infrastructure })+0.19 \times(\text { Information systems })+0.29 \times(\text { Up-to-da }\end{array}$ \\
\hline
\end{tabular}

Figure 4: Constructing Measures of CS Effectiveness of Design Departments

\begin{tabular}{|c|}
\hline 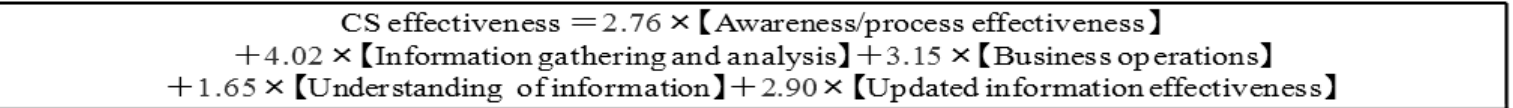 \\
\hline $\begin{aligned} \text { 【 Awareness/process effectiveness } \backslash & =0.27 \times(\text { Improving } 3 \mathrm{M})+0.23 \times(\text { Work procedure }) \\
& +0.24 \times(\text { Standardization of human capacity })+0.25 \times(\text { Shared goal awareness })\end{aligned}$ \\
\hline $\begin{aligned} \text { 【Information gathering and analysis } 】=0.17 \times(\text { Information item })+0.21 \times(\text { Information accuracy }) \\
+0.26 \times(\text { Information volume })+0.15 \times(\text { Analysis expertise })+0.20 \times(\text { Separation by segment })\end{aligned}$ \\
\hline $\begin{aligned} \text { 【 Business operations } 】 & =0.14 \times(\text { Transmitted information })+0.28 \times(\text { Product concep } \mathrm{t}) \\
& +0.40 \times(\text { Information gathering between departments })+0.18 \times(\text { Information analysis })\end{aligned}$ \\
\hline $\begin{array}{l}\text { 【 Understanding of information } \backslash=0.25 \times(\text { Received information })+0.38 \times(\text { Design proposal }) \\
+0.37 \times(\text { Established of a shared language })\end{array}$ \\
\hline $\begin{array}{l}\text { 【 Updated information effectiveness } 】=0.27 \times(\text { Information sharing/centralization }) \\
\quad+0.16 \times(\text { Network infras tructure })+0.28 \times(\text { Information systems })+0.29 \times(\mathrm{Up} \text {-to-date information })\end{array}$ \\
\hline
\end{tabular}

Figure 5: Constructing Measures of CS Effectiveness of Product Pplanning Departments 


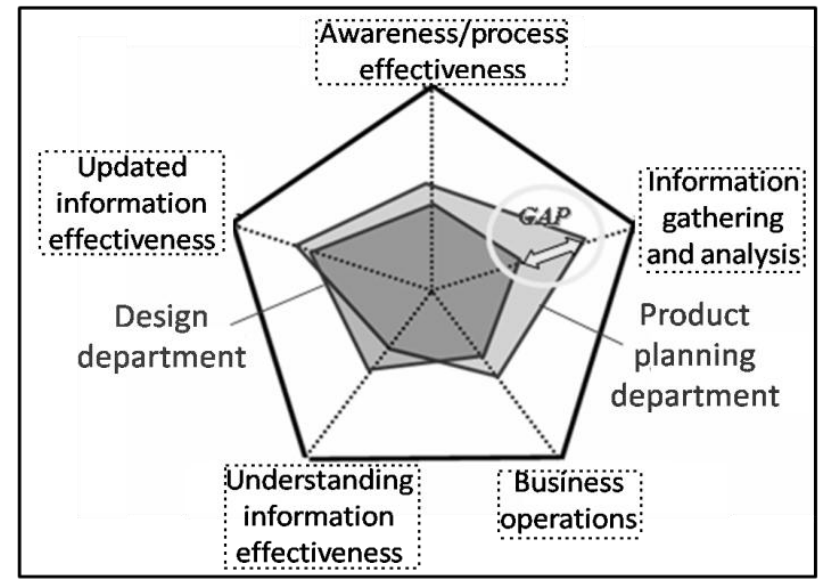

Figure 6: The Measures of CS Effectiveness of Company $P$

\section{VERIFICATION}

The Measures of CS Effectiveness were actually applied at companies in order to measure current levels of CS effectiveness. Three manufacturers participated in the verification process. Participants were asked to rate their current level in terms of a total of 20 evaluation items in response to the question, "Is X currently being achieved in order to boost customer satisfaction?"

Figure 6 shows the results of Company $\mathrm{P}$ (with three product planning departments and two design departments). First, the average values for the 20 -question items were calculated for each division and multiplied by the group coefficients to calculate a total score for each group. Next, each group score was multiplied by the CS effectiveness coefficient to calculate a score for each group. These scores were plotted on a radar chart in order to visualize the gaps between the product planning and design departments at Company $\mathrm{P}$ and identify problem areas.

\section{Characteristics of Company $P$}

1. Understanding of information effectiveness scores were low for both departments

2. There is a large gap between product planning and design departments in terms of information gathering and analysis effectiveness.

Based on the above issues, it was determined that Company P should institute the following policies:

- In order to combat the first issue, Company $\mathrm{P}$ should establish a shared language that can also be understood by the product planning department and simplify product concepts. To address the second issue, Company $\mathrm{P}$ should require that improvements be made to problem areas in its information-gathering network and clarify the meaning of essential information from the design department.

- $\quad$ The Measures of CS Effectiveness were also applied at Company N (with two product planning departments and two design departments) and Company $\mathrm{H}$ (with two product planning departments and three design departments), enabling problem areas and policies to combat these issues to be determined.

\section{CONCLUSION}

The development of Measures of CS Effectiveness enabled the gaps between product planning departments and design departments to be visualized. By actually applying these measures at three companies, the researchers were able to identify problem areas at each as well as offer policies that companies could use to address them. 


\section{AUTHOR INFORMATION}

Akinori Ishikawa is a graduate student of the College of Science and Engineering at Aoyama Gakuin University.

Yuki Morita is a graduate student of the College of Science and Engineering at Aoyama Gakuin University.

Kakuro Amasaka is a Professor in the School of Science and Engineering at Aoyama Gakuin University, Japan. He received his Ph.D. degree in Precision Mechanical and System Engineering, Statistics and Quality Control at Hiroshima University in 1997. His current research and teaching interests are in the general area of production engineering. In particular, he is interested in New JIT. He is a chairman of JOMSA (2008). E-mail: Kakuro_amasaka@ise.aoyama.ac.jp

\section{REFERENCES}

1. K. Amasaka, Proposal of Marketing SQC to Revolutionize Dealers' Sales Activities-A Demonstrative study on Customer Science by utilizing Science SQC, Proceedings of the16th International Conference Production Research. Praha Czech Public, 2007, pp.1-9(CD-ROM)

2. K. Amasaka, Quality of engineer's work and significance of patent application, The 2nd patent seminar, 2002

3. Y. Morita, Constructing Measures of CS Effectiveness to Boost Subjective Quality at Manufacture, Aoyama Gakuin University, 2008

4. K. Anabuki, A Study of Patent Value evaluation Method “A-PPM” for Corporate Strategy, Aoyama Gakuin University, 2007

5. T. Ishizuka, One research on Partnering to Strengthen Japanese Quality Management, Aoyama Gakuin University, 2006

6. M. Kuniyoshi, The product development business model's new proposal, Aomaya Gakuin University, 2006

7. H. Kaneta, The Research on Constructing of the Patent Evaluation m Model, Aoyama Gakuin University, 2006

8. T. Sakatoku, A research on Partnering Model to strengthen Japanese quality management, Aoyama Gakuin University, 2007

9. Shumei Zhang, Core Competence and Linkage Capability : Case Studies of Japanese Companies, Nihon Fukushi University, 1999

10. K. Toshiya, A proposal of partnering algorithm based on Multi Agent System , Kobe University, 2008 


\section{NOTES}

